\title{
Maximizing IT Investment Returns: Strategic Alignment of Information Technology towards Corporate Performances
}

\author{
Mohammad Alryalat ${ }^{1}$, Richmond Adebiaye ${ }^{2, *}$, Haroun Alryalat ${ }^{3}$ \\ ${ }^{1}$ Faculty of Business, Assistant Professor, Al-Balqa Applied University, Salt, The Hashemite Kingdom of Jordan \\ ${ }^{2}$ Information Systems, College of Business and Technology, Parker University, Dallas Tx, United States \\ ${ }^{3}$ College of Information Technology, Dean of IT College, Ajman University, Ajman UAE \\ *Corresponding author: richmond.adebiaye@yahoo.com
}

\begin{abstract}
Information technology (IT) investment and aligning methodologies require thorough understanding of analyses on different parallel present values and strong internal rates of return. E-commerce has given a new dimension to IT investing that elevates the role of strong IT performance as a driver of corporate strategy. Stakeholders concerned with maximizing IT return on investment (ROI) recognize the importance of central, comprehensive information resources to effective strategic business planning. Alignment of corporate and IT strategies is now a vital element of business success. To empirically support this conclusion, this study measures the relationship between strategic alignment of IT investment returns and corporate performance. A Descriptive research design using survey methodology was employed. The study included analyses of variable values involving stakeholders in banks, such as new customers and employees. A Simple Percentage Method, chi-square tests, Tables and weighted average were used to analyze data of at least five (5) banks in Ajman Emirates of UAE to determine the degree of alignment and its impact on the two strategic dimensions. A binary logistic regression analysis using Chan's STROIS model incorporated with Venkatraman's STROBE model was proposed to collect survey data and determine the extent of the strategic alignment. The research results provide empirical evidence that supports the hypothesis that closer alignment between corporate and IT strategies leads to increased IT ROI and improved corporate performance. This relationship holds true for all firms regardless of strategic intent for IT. The study also shows a positive correlation between early adoption of newly emergent technologies and business competitive advantage which leads to positive conclusions that strategic competition is imperative towards corporate performances.
\end{abstract}

Keywords: strategic alignment, corporate performance, IT investment returns, competitive advantage

Cite This Article: Mohammad Alryalat, Richmond Adebiaye, and Haroun Alryalat, "Maximizing IT Investment Returns: Strategic Alignment of Information Technology towards Corporate Performances." American Journal of Applied Mathematics and Statistics, vol. 5, no. 2 (2017): 72-79. doi: 10.12691/ajams-5-2-5.

\section{Introduction}

Information Technology (IT) in the banking sector is now a norm rather than an exception, understandably increasing the focus on maximizing return on investments (ROI) in IT. Risks and uncertainties associated with IT can cause risk-averse managers to demand assurances of high rates of returns before they approve investments in IT systems (Ross \& Breath, 2002). Decision-making on IT investing, like other ventures, has been traditionally characterized by assessing ROI purely on the basis of financial calculations such as the Internal Rate of Return, the Present Value and Net Present Value [9]. Recently, however, organizations increasingly broaden the scope of analyses to include non-financial considerations when deciding whether to invest in IT.

The need to include non-financial factors in a case for IT investment arises from the inherent limitations of sole reliance on financial calculations of ROI. Researchers have found that exclusive use of financial metrics to make such decisions is not only insufficient, it is also a source of quantification difficulty at the implementation stage [1]. In practice, many organizations do go beyond ROI calculations and consider important non-financial indicators when prioritizing projects. For example, Ross and Breath [11] found that 27 of 30 Senior Managers (SM) allocated funds for IT projects perceived to be strategic, and 16 SM's funded projects when they perceived investment in the proposed IT infrastructure to be integrally necessary for the company to meet evolving customer demands, as well as open new businesses.

Literature supports the notion that strategic alignment, corporate performance and competitive advantage are important adjuncts to financial aspects of ROI in IT. A more reliable approach to the question of maximizing returns on IT investments would be to integrate financial and non-financial analyses of ROI [12]. To this end, this study establishes the relationship between alignment of corporate strategies with IT investments and the ROI of such investments. 


\section{Literature Review}

Studies on business-IT alignment (BITA) in the banking sector reveal that banks whose IT strategies and business strategies are aligned are more likely to retain and attract customers and remain competitive [4]. Ever-increasing marketplace banking IT solutions has increased competition among financial institutions, demanding mandatory justification for heavy investments in IT. To maintain a competitve edge, banks are constantly improving existing business processes and innovating new processes. Those that target IT investments to improve competitiveness must ensure alignment of business and IT planning at the strategic, tactical and operational levels. Singh and Desai [13] suggest four parameters for evaluating BITA: addition of value to services and products, enhancement of competitive positioning, reduction of costs and improvement of administrative efficiency, and improvement of managerial effectiveness. In the banking sector, an IT strategy should take into account the bank's business objectives and competitiveness, costs, benefits and risks of the current and future IT processes. Furthermore, it should analyze the IT venture's ability to adapt to current and future banking needs, whether the operation costs of the IT program provide sufficient business value, and ensure compliance with regulatory requirements [13].

Study of BITA in the banking sector is multidirectional. One study examined the relationship between strategic alignment, business strategy and ROI. Another study measured returns for IT investment and corporate performance to provide evidence for aligning business strategy and IT strategy [10]. Evidence from this study remains anecdotal since the demarcation between business strategy, IT strategy, and strategic alignment is unclear. Though there is paucity of theoretical frameworks for studying the nexus between strategic alignment and ROI on IT investment, the theory of dynamic capabilities has been used to establish the relationship between strategic alignment, IT flexibility and IT effectiveness [14]. While Ness [9] found that IT flexibility greatly influences IT effectiveness more than strategic alignment in larger organizations, other studies have found that strategic alignment has a greater effect than other factors irrespective of organization size $[9,10]$.

Most inconsistencies in study results are partially attributable to inconsistent strategy alignment and benefit valuation methodology. Shi and Silvius [12] noted that over 50 models exist for calculating IT benefits. Although some of these models view benefits from IT investment as a function of strategic alignment, a majority of the models fail to address alignment of IT and business strategies as a factor that creates or influences value. This study analyzes the benefits of such alignment for five banks in Ajman Emirates, United Arab Emirates (UAE). To avoid previous empirical inconsistencies found in similar studies, our study employs a more robust integrated model for measuring alignment and its effect on corporate performance.

\section{Methodology}

This study is an empirical assessment of the relationship between strategic alignment of IT ROI and corporate performance by analyzing data of five commercial banks in Ajman Emirate, UAE. The study aims to provide both a conceptual understanding of the strategic alignment on IT investments returns and an empirical definition for commercial bank corporate performance. An overall objective was formulated with respect to the specific research objectives, research questions and research hypotheses. The section also presents the research design and study variables.

\subsection{Overall Objective}

This study focuses on the relationship between strategic alignment of IT investment returns and corporate performance, and seeks supporting empirical evidence. Following are the study's specific research objectives:

\subsubsection{Specific Objectives}

i. To establish whether closer alignment between business and IT strategies lead to increased returns on IT investments.

ii. To determine whether closer alignment between business and IT strategies lead to improved corporate performance.

iii. To determine the relationship between early adoption of new and emerging technology and business competitive advantage.

\subsection{Research Questions}

i. Does closer alignment between business and IT strategies significantly lead to increased returns on IT investments.

ii. Does closer alignment between business and IT strategies significantly lead to improved corporate performance.

iii. Is there any significant relationship between early adoption of new and emerging technology and business competitive advantage.

\subsection{Research Hypotheses}

\section{Hypothesis 1}

$\mathrm{H}_{1}$ 0: Closer alignment between business and IT strategies does not lead to increased returns on IT investments. Against;

$\mathrm{H}_{1}$ 1: Closer alignment between business and IT strategies leads to increased returns on IT investments.

Hypothesis 2

$\mathrm{H}_{2} \mathrm{O}$ : Closer alignment between business and IT strategies does not lead to improved corporate performance. Against;

$\mathrm{H}_{2} 1$ : Closer alignment between business and IT strategies will lead to improved corporate performance

\section{Hypothesis 3}

$\mathrm{H}_{3} 0$ : There is no relationship between early adoption of new and emerging technology and business competitiveness. Against;

$\mathrm{H}_{3}$ 1: There is a relationship between early adoption of new and emerging technology and business competitiveness.

\subsection{STROBE Dimensions [15]}

Aggressiveness refers to the rate of adoption by a business in striving for resources to improve its market 
performance relatively faster than their competitors in the market.

Analysis refers to the expertise of problem solving by having a tendency to search deeper root cause of problems and to come up with best possible solution alternatives.

Defensiveness refers to defensive behavior in terms of emphasizing on cost reduction and consideration of business efficiency.

Futurity refers to reflection of temporal considerations in strategic decision making in terms of the relative emphasis of effectiveness considerations versus efficiency considerations.

Proactiveness refers to activeness behavior in participation in emerging industries and continuous search for market opportunities with regard to changing market trends.

Riskiness refers to the extent of riskiness reflected in various resource allocation decisions as well as choice of products and markets.

\subsection{Research Design}

The research will adopt the descriptive research design using survey methodology for an empirical assessment of the relationship between strategic alignment on IT investment returns and corporate performance. Krueger \& Casey [6] say the descriptive research design best enables collection of numerical data related to views, attitudes, perceptions and opinions from study respondents. The obtained data will be analyzed objectively to address the above stated research questions by asserting generalizations that can be drawn into conclusions.

\subsection{Study Variable Values}

The study is structured to have three sets of variables: dependent variable, independent variables and intervening variables. The dependent variable is the rating of returns on IT investments (Business returns).

The independent variables include STROBE dimensions including business alignment rating in: aggressiveness, analysis, defensiveness, futurity, proactiveness and riskiness. The other business alignment ratings investigated are: IT expertise level, satisfaction of IT values, IT system quality, new IT emerging innovations, and IT adoption.

Intervening variables include socio-demographic factors of IT and business stakeholders, including age, education level, gender, duration of IT usage and socio-economic status of IT professionals and IT managers.

\subsection{Study Sample}

The sample units in this study include: IT and Business Stakeholders, management \& directors in banks, new customers and bank employees. Due to the large concentration of banking services in the Ajman, UAE and due to the lack of sufficient time and resources, a sample size of 150 individuals was deemed adequate for conducting this research. Mugenda (2003) suggested that a sample size of about $150-200$ participants is suitable for an empirical descriptive research design. The sample size of 150 is mainly persons working in banks, bank customers and bank management teams.

\section{Results}

Data analysis and interpretation of the results is presented in the following categories: reliability and validity tests, analysis of socio-demographic factors and analysis of data concerning the research objectives.

\subsection{Reliability and Validity Tests}

The collected data was filtered and coded using SPSS statistical software. Data reliability and validity was assessed using the Cronbach's alpha test.

Reliability tests showed that most of the variables; overall variables $(\alpha=0.913)$, dependent factors $(\alpha=0.760)$, Independent factors including the STROBE dimensions $(\alpha=0.883)$, and the socio-demographic factors $(\alpha=0.814)$ possess greater than 0.7 alpha value of reliability. Thus, the data had more than the $70 \%$ reliability, validity, and feasibility attributes necessary for accurate analysis, allowing use of the information to find answers to our research questions. (Table 1 )

\subsection{Socio-demographic Factors}

Socio-demographic data was organized using a frequency table and descriptive statistics. Table 2 demonstrates the frequency distribution and summarizes the mean and standard deviation of the four socio-demographic factors sought in this study.

The gender of respondents were 76 female banking stakeholders (50.7\%) and 74 male banking stakeholders, with relative frequency of $49.3 \%$. Gender has a mean of 1.51 and standard deviation of 0.50 showing that there is gender parity in respondents in the study of strategic alignment on IT investment returns and corporate performance in banking sector. Gender parity is indicated in the pie chart below. (Figure 1)

Age distribution in the study showed normality. The modal age group of the respondents was 40-49 years while the minority age group in this study was 20-29 years. Respondents' average age was 31.37 (Mean=41.37 \& $\mathrm{SD}=4.97)$. The histogram below shows the age distribution of the banking stakeholders. (Figure 2)

Table 1. Cronbach's alpha tests for reliability

\begin{tabular}{|l|c|c|}
\hline Variable type & Cronbach's Alpha & N of Variables \\
\hline Dependent factors & 0.760 & 6 \\
\hline Independent factors & 0.883 & 40 \\
\hline Socio-demographic factors & 0.814 & 40 \\
\hline Overall & 0.913 & 150 \\
\hline
\end{tabular}


Table 2. Frequency distribution and descriptive statistics of socio-demographic factors

\begin{tabular}{|c|c|c|c|c|c|}
\hline Factor & Attribute & Freq & Percent & Mean & Standard deviation \\
\hline \multirow{3}{*}{ Gender } & Male & 74 & 49.3 & \multirow{3}{*}{1.51} & \multirow{3}{*}{0.50} \\
\hline & Female & 76 & 50.7 & & \\
\hline & Total & 150 & 100.0 & & \\
\hline \multirow{5}{*}{ Age } & $20-29$ & 23 & 15.3 & \multirow{5}{*}{41.37} & \multirow{5}{*}{4.97} \\
\hline & $30-39$ & 37 & 24.7 & & \\
\hline & $40-49$ & 56 & 37.3 & & \\
\hline & $50-59$ & 34 & 22.7 & & \\
\hline & Total & 150 & 100.0 & & \\
\hline \multirow{4}{*}{ Education level Socio-economic status } & Diploma & 92 & 61.3 & \multirow{4}{*}{1.43} & \multirow{4}{*}{0.58} \\
\hline & Degree & 91 & 34.0 & & \\
\hline & Post graduate & 7 & 4.7 & & \\
\hline & Total & 150 & 100.0 & & \\
\hline \multirow{4}{*}{ Socio economic status } & Low & 51 & 34.0 & \multirow{4}{*}{1.94} & \multirow{4}{*}{0.77} \\
\hline & Middle & 60 & 40.0 & & \\
\hline & High & 39 & 26.0 & & \\
\hline & Low & 51 & 34.0 & & \\
\hline
\end{tabular}

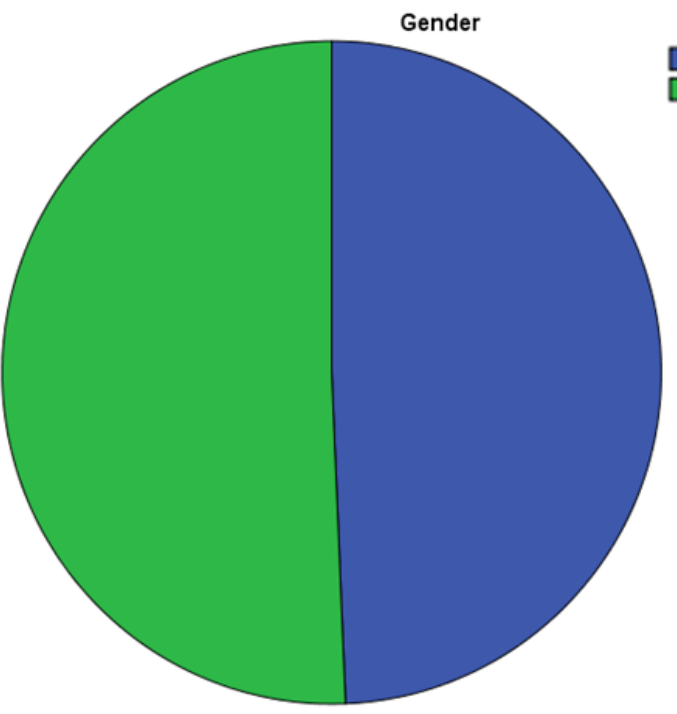

$\square$ Male
$\square$ Female

Figure 1. Pie chart of gender distribution

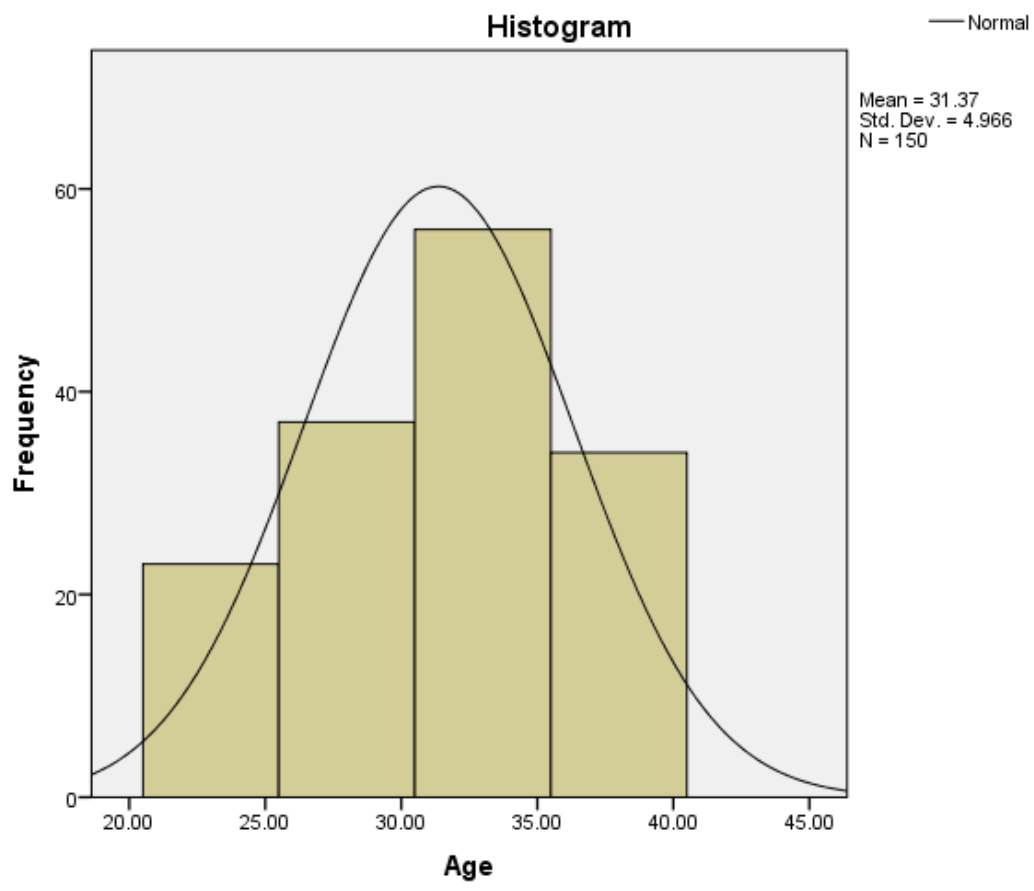

Figure 2. Histogram of gender distribution 


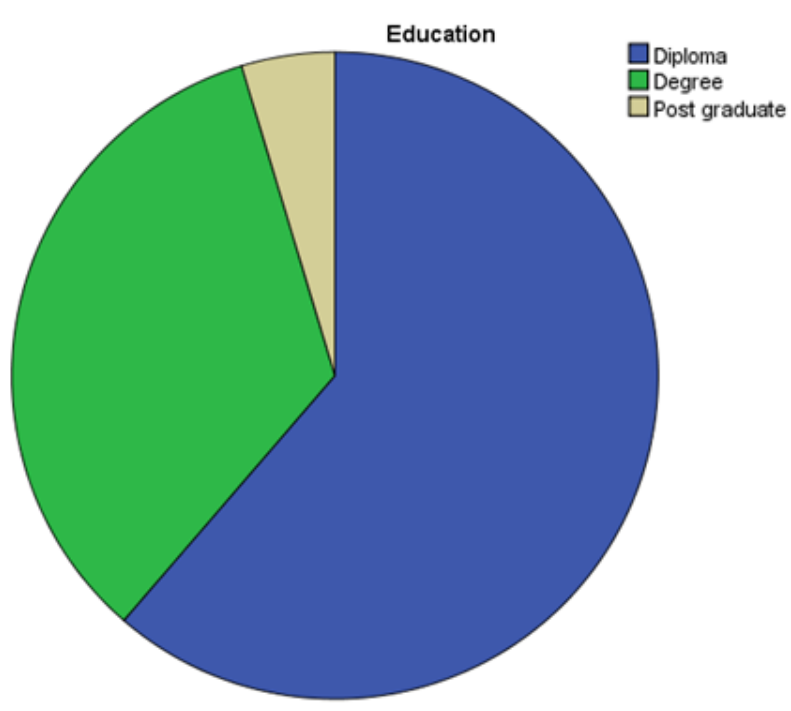

Figure 3. Pie chart of education level distribution

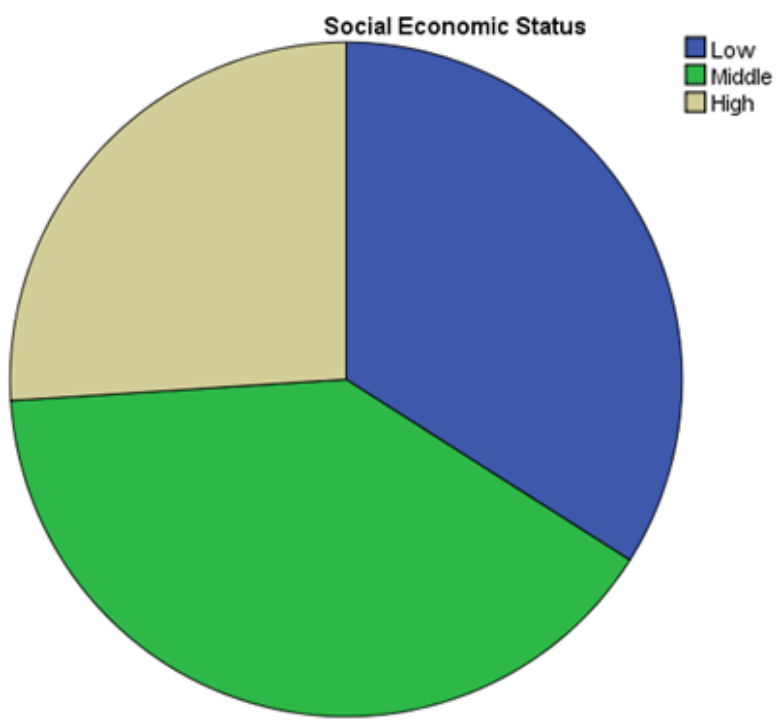

Figure 4. Pie chart of socio-economic distribution

Study respondents fit into one of three levels of education: diploma, degree, post-graduate. Most respondents were at the diploma level, with a frequency of 92 (61.3\%). Those at the degree level totaled 51 (34.0\%). A minority of respondents, 7 (4.7\%), were at the post-graduate degree level. This shows that most banking stakeholders have diploma-level education. The pie chart below displays the education level of study respondents. (Figure 3)

The highest number of respondents, $60(40.0 \%)$, are in the middle level of socio-economic status, followed by the low socio-economic status at 51 (34.0\%). Respondents in the high socio-economic status totaled 39 (26.0\%). The pie chart below displays the distribution of socioeconomic status of the respondents. (Figure 4)

\subsection{Data Analysis Related to Research Objectives}

The data regarding the research questions were analyzed using both descriptive and inferential statistics. To ascertain the significant factors that affect the relationship between the strategic alignment on IT investment returns and corporate performance, Chi-square tests and binary logistic regression of the Strobe factors were used.

Results in Table 3 show that four of the STROBE dimensions including: strategic alignment due to aggressiveness $((1)=17.917, \mathrm{p}=0.000)$, strategic alignment due to defensiveness $(\chi(1)=10.545, \mathrm{p}=0.001)$, strategic alignment due to proactiveness $(\chi(1)=33.919, \mathrm{p}=0.000)$ and strategic alignment due to riskiness $(\chi(1)=4.189$, $\mathrm{p}=0.009)$ significantly influence IT investment returns and corporate performance. Strategic alignment due to analysis $((1)=2.152, \mathrm{p}=0.142)$ and strategic alignment due to futurity dimension $(\chi(1)=0.157, \mathrm{p}=0.692)$ are not significant in influencing IT investment returns and corporate performance.

Within other strategic alignment ratings: satisfaction of IT values $((1)=3.921, \mathrm{p}=0.023)$, new IT emerging innovations $(\chi(1)=6.108, \mathrm{p}=0.003)$ and new IT adoption $(\chi(1)=11.250, \mathrm{p}=0.001)$ were found to be significant in leading IT investment returns and corporate performance. On the other hand, IT expertise level $((1)=2.259$, $\mathrm{p}=0.118)$ and IT system quality $(\chi(1)=1.096, \mathrm{p}=0.295)$ are not significant in affecting IT investment returns and corporate performance. 
Table 3. Cross tabulation and Chi-square results for relationship between the strategic alignment factors and IT investment returns and corporate performance

\begin{tabular}{|c|c|c|c|c|c|c|c|}
\hline \multicolumn{5}{|c|}{ Cross tabulation } & \multicolumn{3}{|c|}{ Chi-Square Tests } \\
\hline & & \multicolumn{3}{|c|}{ IT investment returns \& Corporate performance } & \multirow[t]{2}{*}{ Value } & \multirow[t]{2}{*}{ df } & \multirow[t]{2}{*}{ Sig. } \\
\hline & & High & Low & Total & & & \\
\hline \multirow{3}{*}{ STROBE Factor 1: Aggressiveness } & High & 72 & 39 & 111 & & & \\
\hline & Low & 10 & 29 & 39 & $17.917^{\mathrm{a}}$ & 1 & .000 \\
\hline & Total & 82 & 68 & 150 & & & \\
\hline \multirow{3}{*}{ STROBE Factor 2: Analysis } & High & 17 & 8 & 25 & & & \\
\hline & Low & 65 & 60 & 125 & $2.152^{\mathrm{a}}$ & 1 & .142 \\
\hline & Total & 82 & 68 & 150 & & & \\
\hline \multirow{3}{*}{ STROBE Factor 3: Defensiveness } & High & 64 & 36 & 100 & & & \\
\hline & Low & 18 & 32 & 50 & $10.545^{\mathrm{a}}$ & 1 & .001 \\
\hline & Total & 82 & 68 & 150 & & & \\
\hline \multirow{3}{*}{ STROBE Factor 4: Futurity } & High & 8 & 8 & 16 & & & \\
\hline & Low & 74 & 60 & 134 & $.157^{\mathrm{a}}$ & 1 & .692 \\
\hline & Total & 82 & 68 & 150 & & & \\
\hline \multirow{3}{*}{ STROBE Factor 5: Proactiveness } & High & 70 & 27 & 97 & & & \\
\hline & Low & 12 & 41 & 53 & $33.919^{\mathrm{a}}$ & 1 & .000 \\
\hline & Total & 82 & 68 & 150 & & & \\
\hline \multirow{3}{*}{ STROBE Factor 6: Riskiness } & High & 14 & 26 & 41 & & & \\
\hline & Low & 68 & 42 & 110 & $4.189^{\mathrm{a}}$ & 1 & .009 \\
\hline & Total & 82 & 68 & 150 & & & \\
\hline \multirow{3}{*}{ IT expertise level } & High & 14 & 6 & 20 & & & \\
\hline & Low & 68 & 62 & 130 & $2.259^{\mathrm{a}}$ & 1 & .118 \\
\hline & Total & 82 & 68 & 150 & & & \\
\hline \multirow{3}{*}{ Satisfaction of IT values } & High & 34 & 23 & 57 & & & \\
\hline & Low & 48 & 45 & 93 & $3.921^{\mathrm{a}}$ & 1 & .023 \\
\hline & Total & 82 & 68 & 150 & & & \\
\hline \multirow{3}{*}{ IT system quality } & High & 40 & 39 & 79 & & & \\
\hline & Low & 42 & 29 & 71 & $1.096^{\mathrm{a}}$ & 1 & .295 \\
\hline & Total & 82 & 68 & 150 & & & \\
\hline \multirow{3}{*}{ New IT emerging innovations } & High & 43 & 22 & 65 & & & \\
\hline & Low & 39 & 46 & 85 & $6.108^{\mathrm{a}}$ & 1 & .003 \\
\hline & Total & 82 & 68 & 150 & & & \\
\hline \multirow{3}{*}{ New IT adoption } & High & 51 & 28 & 79 & & & \\
\hline & Low & 31 & 40 & 71 & 11.250 & 1 & .001 \\
\hline & Total & 82 & 68 & 150 & & & \\
\hline
\end{tabular}

Using the results above, a binary logistic regression analysis using the Venkatraman's STROBE with the STROIS model will be analyzed to determine the effect of strategic alignment on IT investment returns and corporate performance.

\subsection{Binary Logistic Regression Analysis Results}

Significant variables to be fitted in the binomial logistic regression model the effect of strategic alignment on IT investment returns and corporate performance are: strategic alignment due to aggressiveness, strategic alignment due to defensiveness, strategic alignment due to proactiveness and strategic alignment due to riskiness from the STROBE dimensions as well as; satisfaction of IT values, new IT emerging innovations and new IT adoption.

A binary logistic regression analysis revealed strategic alignment due to aggressiveness $(\beta=0.347, \mathrm{p}=0.000)$, proactiveness $(\beta=1.327, p=0.000)$ riskiness $(\beta=0.131$, $\mathrm{p}=0.005)$, satisfaction of IT values $(\beta=1.098, \mathrm{p}=0.000)$, and new IT adoption $(\beta=0.989, p=0.000)$ were significant in affecting the strategic alignment on IT investment returns and corporate performance. However, strategic alignment due to defensiveness $(\beta=0.537, p=0.102)$ and new IT emerging innovations $(\beta=-0.078, p=0.062)$ were only significant when associated with IT investment returns and corporate performance; they did not have a significant effect on strategic alignment on IT investment returns and corporate performance. 
Table 4. Binary logistic regression results

\begin{tabular}{|c|c|c|c|c|c|}
\hline Independent variables & B & S.E. & df & Sig. & $\operatorname{Exp}(B)$ \\
\hline Aggressiveness & .347 & .073 & 1 & .000 & 1.414 \\
\hline Defensiveness & .537 & .190 & 1 & .102 & .585 \\
\hline Proactiveness & 1.327 & .284 & 1 & .000 & 3.769 \\
\hline Riskiness & .131 & .034 & 1 & .005 & 1.139 \\
\hline Satisfaction of IT values & 1.098 & .124 & 1 & .000 & 2.998 \\
\hline New IT emerging innovations & -.078 & -0.001 & 1 & .062 & .925 \\
\hline New IT adoption & .989 & .212 & 1 & .000 & 2.689 \\
\hline Constant & -9.994 & .576 & 1 & .044 & 0.000 \\
\hline
\end{tabular}

\section{Summary: Results and Conclusions}

Most of the study variables, the overall variables, dependent factors, and independent factors, including the STROBE dimensions and socio-demographic factors, possess an alpha value greater than $0.7(\alpha>0.7)$. Therefore, the data had above the necessary $70 \%$ reliability, validity and feasibility attributes for accurate analysis, allowing us to use the information to answer our study's research questions.

The genders of study respondents were $50.7 \%$ female and $49.3 \%$ male. This showed gender parity exists the study of strategic alignment on IT investment returns and corporate performance in banking sector. The age distribution of the study participants showed normality. The modal age group of the respondents was 40-49 years with an average the age (Mean=41.37 \& SD=4.97). A majority of respondents were diploma education level holders, followed by those with a degree education level. A minority held post graduate degrees. This shows that most of the banking stakeholders are of diploma education level. Finally, most respondents are of mid-level socioeconomic status, followed by low socio-economic status. The lowest number of respondents were of high socioeconomic status.

\section{Hypothesis 1}

$\mathrm{H}_{1} 0$ : Closer alignment between business and IT strategies does not lead to increased returns on IT investments. Against;

$\mathrm{H}_{1} 1$ : Closer alignment between business and IT strategies leads to increased returns on IT investments.

From our study results, the research showed that four of the STROBE dimensions including strategic alignment due to: aggressiveness, defensiveness, pro-activeness and riskiness had p-values that were less than 0.05. Therefore, the study rejects the null hypothesis (H10) and concludes that closer alignment between business and IT strategies leads to increased returns on IT investments.

\section{Hypothesis 2}

$\mathrm{H}_{2} 0$ : Closer alignment between business and IT strategies does not lead to improved corporate performance. Against;

$\mathrm{H}_{2}$ 1: Closer alignment between business and IT strategies will lead to improved corporate performance.
The study also realized that strategic alignment ratings on satisfaction of IT values, new IT emerging innovations and new IT adoption had p-values less than $0.05(\mathrm{p}<0.05)$. Therefore, the research rejects the null hypothesis (H20) and concludes that closer alignment between business and IT strategies will lead to improved corporate performance.

\section{Hypothesis 3}

$\mathrm{H}_{3} 0$ : There is no relationship between early adoption of new and emerging technology and business competitiveness. Against;

$\mathrm{H}_{3} 1$ : There is a relationship between early adoption of new and emerging technology and business competitiveness.

The study found that new IT emerging innovations and new IT adoption were significantly associated with business competitive advantage in Chi-square analysis. However, in binomial logistic analysis, it was found that new IT adoption was very significantly related to business competitive advantage. Therefore, the study general concludes that there is a positive relationship between early adoption of new and emerging technology and business competitiveness.

\section{Binary Logistic Regression Analysis}

A binary logistic regression analysis showed that when strategic alignment due to aggressiveness increases by one, the strategic alignment on IT investment returns and corporate performance increased by $1.414(\operatorname{Exp}(\beta)=1.414)$. Similarly strategic alignment due to pro-activeness $(\operatorname{Exp}(\beta)=3.769)$ riskiness $(\operatorname{Exp}(\beta)=1.139)$, satisfaction of IT values $(\operatorname{Exp}(\beta)=2.998)$, and new IT adoption $(\operatorname{Exp}(\beta)=2.689)$ were found to be positively and significantly related the strategic alignment on IT investment returns and corporate performance.

\section{References}

[1] Chabrow, E. (March 24, 2003). IT staffs lack financial chops for project analysis, Information Week, 932, 20.

[2] Chan, Y. E., Huff, S. L., Barclay, D. W., \& Copeland, D. G. (1997). Business Strategic Orientation, Information Systems Strategic Orientation, and Strategic Alignment. Information Systems Research, 8(2): 125-150.

[3] Hair, J.F., Anderson, R.E., Tatham, R.L. and Black, W.C. (1998), Multivariate Data Analysis, 5th ed., Prentice-Hall, Englewood Cliffs, NJ.

[4] Iman N, Hartono J. (2007). Strategic Alignment Impacts on Organizational Performance in Indonesian Banking Industry. Gadjah Mada International Journal of Business 2007; 9(2): 253-272.

[5] Kothari, C. R. (2004). Research methodology: Methods and techniques. New Age International.

[6] Krueger, R. A., \& Casey, M. A. (2014). Focus groups: A practical guide for applied research. Sage.

[7] Morgan, R. E., \& Strong, C. A. (2003). Business Performance and Dimensions of Strategic Orientation. Journal of Business Research, 56(3): 163-176.

[8] Mugenda, O. M. (2003). Research methods: Quantitative and qualitative approaches. African Centre for Technology Studies.

[9] Ness, L. R. (2005). Assessing the relationships among information technology flexibility, strategic alignment, and information technology effectiveness. From ProQuest Dissertations \& Theses database. (No. AAT 3178531). 
[10] Pierce, A.C. (2002). The effect of business and information technology strategic alignment on information technology investment returns and corporate performance. From ProQuest Dissertations \& Theses database. (No. AAT 3058558).

[11] Ross, J.W. \& Breath, C.M. (2002). Beyond the Business Case: New Approaches to IT Investment, MIT Sloan Management Review, 51-59.

[12] Shi, N. \& Silvius, G. (2011). Enterprise IT governance, business value and performance measurement. Hershey, Pa: IGI Global (701 E. Chocolate Avenue, Hershey, Pennsylvania, 17033, USA.
[13] Singh, A. \& Desai, B. (2012). Strategic Business Alignment: A study of role of IT in Strategic Business Alignment in Banking sector of India. Global Journal for Research Analysis, 2, 1, 98-101.

[14] Tallon, P. P., \& Kraemer, K. L. (2003). Using flexibility to enhance the alignment between information systems and business strategy: Implications for IT business value. Center for Research on Information Technology and Organizations (CRITO), University of California, Irvine.

[15] Venkatraman, N. (1989). Strategic Orientation of Business Enterprises: The Construct, Dimensionality, and Measurement. Management Science, 35 (8): 942-962. 